\title{
Digital Health Platform Complementor Strategies and Effectual Reasoning
}

\author{
Anssi Smedlund, Petra Turkama, Heini Ikävalko \\ Center for Knowledge and Innovation Research (CKIR), Aalto University School of Business, Helsinki, Finland \\ Email: anssi.smedlund@aalto.fi
}

How to cite this paper: Smedlund, A., Turkama, P. and Ikävalko, H. (2018) Digital Health Platform Complementor Strategies and Effectual Reasoning. Journal of Service Science and Management, 11, 360-373. https://doi.org/10.4236/jssm.2018.114025

Received: June 13, 2018

Accepted: July 28, 2018

Published: July 31, 2018

Copyright (C) 2018 by authors and Scientific Research Publishing Inc. This work is licensed under the Creative Commons Attribution International License (CC BY 4.0).

http://creativecommons.org/licenses/by/4.0/

(c) (i) Open Access

\begin{abstract}
Digital platform based markets are starting to dominate many sectors of the economy and society. Apple Healthkit and Google Fit are examples of fitness data platforms and focal points of connected preventive healthcare markets. Application developers are increasingly complementing platforms instead of bringing stand-alone services to the market. However, studies on these complementors' strategies are still rare. This paper examines complementors' strategies in joining digital platforms in preventive healthcare sector through an exploratory case study. The strategies are created by identifying themes and subthemes from interviews with complementors, and evaluating them through effectual reasoning lens. Effectual reasoning is selected as the assessment approach due to increased ecosystem complexity and strategic choices caused by accumulating end-user data, processes, user experience and emerging communities. This paper states that complementors can attach their application not only to the stable technological core maintained by the platform owner, but also dynamic elements being co-created among other platform participants. The paper contributes to the ongoing discussion and platform literature on complementor strategies.
\end{abstract}

\section{Keywords}

Preventive Healthcare Platforms, Complementor Strategies, Effectual Reasoning

\section{Introduction}

In traditional economic view, market is considered as pre-existing stable environment, where demand and consumer tastes can be predicted. Contemporary digital economy and emerging platforms challenge this perception. Research on software service platforms where the participants connect to an online platform for definitions, see [1], has shown to be capable of creating markets (e.g. Air- 
$\mathrm{BnB}$ ) that lock participants in with social processes (e.g. Facebook), and bring about new latent end user needs (e.g. Amazon.com). This means that innovation dynamics on software service platforms, labeled as "service platforms" in this paper for brevity, differ from traditional markets.

Platform complementors offer services that extend the functionality of a platform, and increase its' network effects. Complementary goods and services offer more value to the consumer as a joint offering than separately. The adoption of new technologies and the growth of the market are directly affected by the degree to which complementary products and services are available. Often these complementors create new markets and needs with their products and services. In such emerging markets, complementors have to deal with constant flux, change and uncertainty. Various platforms overlap each other, and companies participate in several platforms and cross-connect with firms and other market actors from numerous platforms [1] [2]. New service platforms envelop and extend the features of existing platforms [3]. Large firms such as Google and Apple use service platforms to differentiate and re-position themselves in order to sustain their leadership in the business ecosystem. Service platforms are the focal touch points where value is appropriated from markets, and many firms own several platforms to serve different parts of their ecosystems [4].

Service platform is a digital venue where interdependent offerings are co-created and delivered. The co-created value is greater than the value of each asset alone. Previous research in engineering and economics disciplines does not fully explain how offerings emerge in service platforms. The economic perspective considers platforms as mediating one-sided, two-sided or multi-sided markets and the research focus is on pricing mechanisms and emergence. An engineering perspective considers platforms from the modular production point of view, where the platform is structurally stable, and innovation occurs in the modules [5]. However, to date, service platforms seem to have developed in evolutionary manner, and social and behavioral processes among platform participants are the critical success factors. Thus novel theoretical and conceptual approaches for investigating these dynamics are needed.

This paper presents an entrepreneurial logic approach to service platforms in an effort to highlight the role of a platform as an asset for the orchestration of value co-creation in the business ecosystem. When orchestrating participants' assets, service platform provides an integrated offering that solves a shared problem in the business ecosystem. Examples of the shared problems are mobile payment and location services in the case of Uber and digital trust in the cases of AirBnB and Betfair.com. Solving a shared problem provides superior value for all partners and simultaneously makes the incumbent business models obsolete.

Complementors connect their service to the service platform's core element that is in the engineering literature defined as fixed core technology with low variety, owned by a legal entity and protected with intellectual property rights (IPR's) [6]. In case of service platforms, complementors can connect services also to intangible, non-technical parts of the platform, such as user community or 
accumulated data in the case of third party facility service providers at AirBnB. The idea of platform core is thus extended to include broader set of characteristics than just technology. These elements are constantly changing and evolving as the platform evolves. Tapping onto these opportunities requires application of entrepreneurial logic.

We introduce the notion of effectual reasoning as an applicable entrepreneurial logic. It is a stream in management theory that explains how entrepreneurs reason about transforming a seemingly radically new idea into successful business in a non-existing market [7]. Effectual reasoning focuses on company's assets, talents and abilities, as well as on the ways to connect them to the identified opportunities in the marketplace without firm pre-defined goals [7]. Effectual reasoning leverages complementary assets and synergies for novel opportunities for value creation. We argue that effectual reasoning provides a suitable framework for mapping digital service platform ecosystems, and help to categorize complementors platform strategies.

To summarize, the discussion on complementors role in service platforms has been dominated by engineering and economics perspectives. We claim that entrepreneurial logic perspective offers an interesting new dimension to the current understanding. This motivates us to look at digital service platforms from a novel perspective, and contribute to the less studied area of platform complementor strategies through effectual reasoning framework [7]. Empirical data for this paper is collected in interviews with seven application developers complementing or planning to complement either Apple Healthkit or Google Fit platforms.

This study contributes to the emerging academic body of knowledge about service platforms and advances the theory development of the topic. Specifically, this paper suggests novel approach to complementors, and contributes to management of innovation in platforms. It presents an unprecedented application of effectual reasoning in the context of digital service platforms. With this we contribute to better understanding of complementors platform strategies, and more specifically answer the question: How does effectual reasoning support complementors platform strategy formation? Managerial implications include increased awareness of the mechanisms of how new value configurations emerge, and support for platform strategy planning.

The paper is organized as follows: First, we present the role of complementors and effectual reasoning in service platforms. Second, we review the results of the interview study among companies complementing a preventive healthcare platform [8]. Third, strategies for complementors are presented by reflecting the themes and subthemes arising from the interviews with Sarasvathy's [7] principles of effectual reasoning. Lastly brief discussion and conclusion is presented.

\section{Service Platforms and Effectual Reasoning}

\subsection{Complementors in Service Platforms}

Service platform is a set of components that provides a service delivery architec- 
ture (core) and integrated IT capabilities, as well as an interface for the creation of services that cross technology and network boundaries (complementarities). Service platforms differ from technological platforms in their openness, wider variety of participants, complexity and uncertainty due to dynamic, often non-technological core elements.

Much of the research on technology platforms focuses on the core technologies. The concept of core comes from studies with Intel and its microchips [9] where non-replaceable core technology integrated other devices and complementary technologies and services. In this engineering oriented view, platforms are composed of onion-like multilayered structures in which the technological core element is necessary for complementary technologies that extend the functionality and attractiveness of the platform.

In service platforms alike, the system architecture is based on a technology core that the platform owner is able to alter if needed e.g. [10]. However, a part of the core elements are not technology based, but rather customer focused, including back-end processes (e.g. reservations, logistics and billing) and flexible front end (e.g. Amazon.com personalized home page) for each participant [11], as well as the social network and community around the platform [12]. Furthermore, digital user experience (UX) can be considered as core element of a digital platform, since most platform owners provide standards for UX to anyone joining the platform.

The extension of core elements to dynamically changing elements allows conceptualizing service platforms as orchestration devices for service systems. Service systems, in their respect, are “...value-co-creation configurations of people, technology, value propositions connecting internal and external service systems, and shared information (e.g., language, laws, measures, and methods)" ([13], p. 18). The service platform owner orchestrates value co-creation relationships in the business ecosystem with boundary resources to its fixed and dynamic core elements, and thus enabling several simultaneous service systems in the ecosystem.

Complementors are businesses that directly sell a product (or products) or service (or services) that complement the product or service of another company by adding value to mutual customers. With multiple complementors contributions, the business ecosystem around a service platform develops in an evolutionary fashion, with selection and retention of participants when new offerings are created, developed and delivered. Each transaction in the platform can be recorded and utilized in improving the core elements. This implies that the relationship between the complementor and the platform owner is not an anonymous buy-sell relationship, but a quasi-firm type of relationship c.f. [14], where the governance mechanisms can be social or institutional in addition to market-based mechanisms. In other words, the software architecture of the service platform is tightly coupled with the platform governance that extends over the organizational boundaries of the platform owner [3]. Platform and ecosystem strategists further agree that complementors should be encouraged to establish 
formal relationships [1] [15]. Relationships such as technological partnerships and alliances drive innovation and collaboration, as increasing interconnectivity fosters the exchange in the ecosystem.

With these distinct characteristics, the innovation activities shift on the complementors that effectively build the ecosystem around the platforms. The ecosystem around the service platform is in constant flux as each transaction and new offering development affects the core elements, which in turn affect the behavior of the platform owner and complementors. Therefore, service platform poses an environment that is changing and uncertain. In this environment, the key questions for complementors are the decisions on the strategies to engage with the platforms, and business model needed to generate profits with complementary assets.

\subsection{Effectual Reasoning in Service Platforms}

Effectuation refers to entrepreneurial logic in creating new products, companies or markets [7] [16]. Effectual reasoning is a transformative type of strategy to cope in uncertain environment, involving low prediction and high-control [17]. Overall, effectuation rests on the logic of control [7]. Thus, instead of predicting the future, effectuator focuses on those aspects that are controllable in the unpredictable future. As Sarasvathy [7] points out one of the core principles of effectuation: "To the extent we can control future, we do not need to predict it". Thus, in effectual logic, a consistent set of ideas, instead of clearly specified goals, form a basis for action [16].

Other core principles in the theory of effectuation are the Affordable loss, Strategic alliances and the Exploitation of contingencies [7]. Following the Affordable loss-principle, effectuation defines how much loss is affordable and, within those limits, experiments as much as possible. Taking the principle of strategic alliances in action means highlighting the partnerships with those people and organizations that are ready to commit to working with you. Exploiting contingencies means that instead of exploiting pre-existing knowledge, focusing on contingencies will bring unexpected sources of competitive advantage over time [7]. Effectively the principles map the dimensions for strategic options that emerge from the companies operating environment. Effectual reasoning contrasts with causal reasoning, a predictive strategy, which assumes that risks and uncertainties can be reduced to a minimum with planning and assessment of the markets. Causal reasoning works well when the market is in a predictable situation [18].

Semantically, service platform is an asset orchestration device in the business ecosystem that is forming around the platform. Accumulated user data, front end user experience, back-end processes and the developed community are the dynamic core elements that the complementor is able to use in order to develop compatible complements. Simultaneously, these elements pose changes in the platform architecture, forming a dynamically evolving and complex environment. By following the logic of the effectual reasoning [17] [19] [20] [21], the 
ever changing platform constrains and opportunities provide input for the innovating complementors. Figure 1 summarizes the effectuation process illustration.

In the context of dynamically evolving service platforms, complementors' strategy requires co-creative approach in which the initial strategy is being used as a starting point and the full strategy is allowed to emerge [22]. Previous literature includes both empirical and conceptual studies using effectuation theory in strategy formulation [18]. For example, the study of Wiltbank et al. [23] showed how the use of predictive vs. non-predictive control strategy effected the outcomes of angel investors. Maine et al. [24] study showed how entrepreneurs iteratively make use of both effectuation and causation principles in interaction with their evolving environments and that effectuation principles can be used in coping with high technological and marked uncertainties.

\section{Empirical Study on Preventive Healthcare Platform Complementors}

The empirical study was conducted during fall 2014 as a part of thesis work [8] when Apple Healthkit and Google Fit had been recently introduced to the market. The objective of the study was to identify the strategies available for the firms complementing the emerging preventive healthcare platforms. Case companies included both start-ups that were already complementing the platforms $(\mathrm{N}=3)$ and established companies that were not complementing, but were interested in doing so $(\mathrm{N}=4)$. All companies were based in Finland and were selected with convenience sampling based on responses to inquiries and accessibility for the researchers. The interviewees were in senior management positions in their companies and in a position to decide on their company's platform strategies.

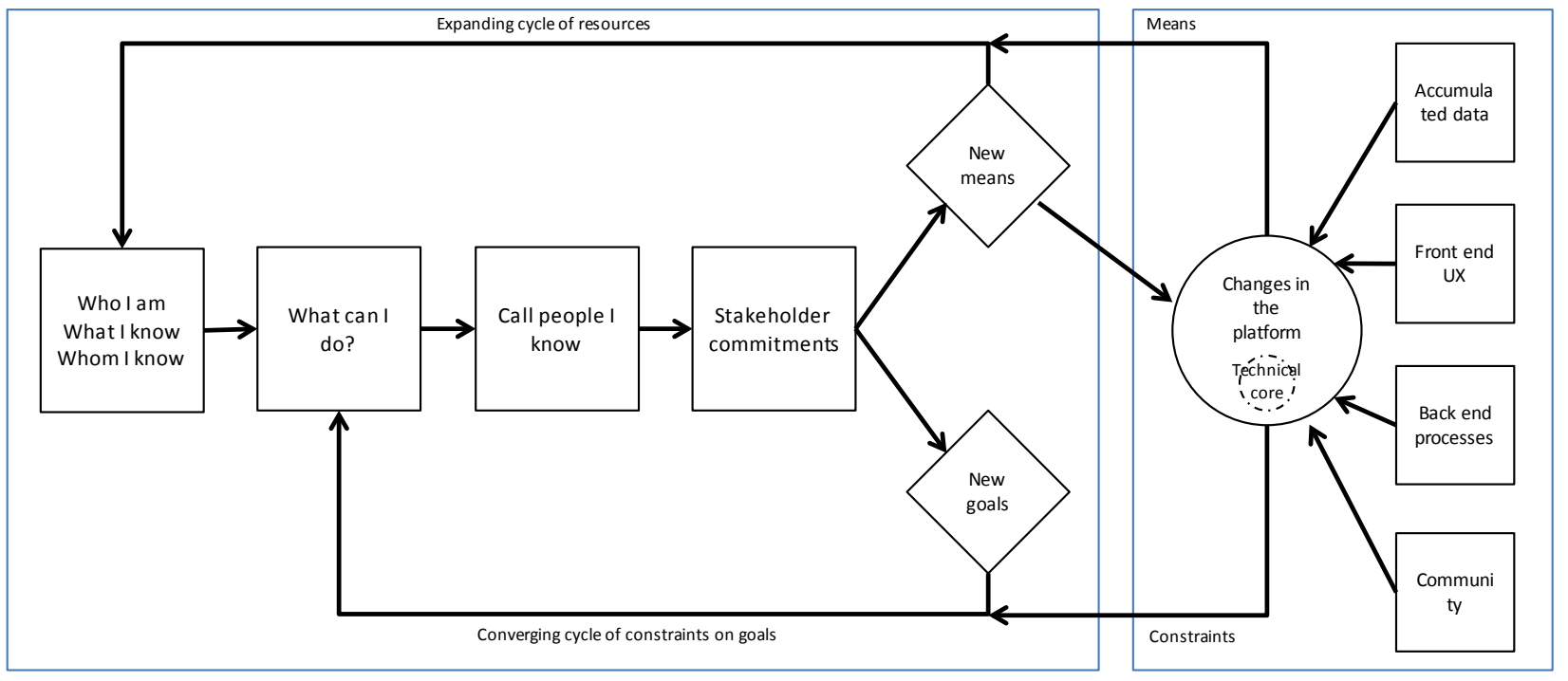

Effectuation process (e.g. Wiltbank et al. 2006)

Evolving digital platform causing uncertain environment

Figure 1. Effectuation in action, service platform perspective (Wiltbank et al. 2006, modified). 
The descriptions of Apple Healthkit, Google Fit and one domestic service platform were used as a starting point in the explorative interviews. The researcher presented each of the platforms, including information about connectivity, partnerships, data privacy and current business use of the platforms. The descriptions were discussed with the interviewee before proceeding with the interview. This provided common ground to the interviews and acted as a warm-up for discussion. Each of the three platforms were discussed separately from the point of view of the interviewee's business. The questions were broad and open-ended letting the interviewee talk about whatever came to their mind on the topic. The interviews were audio-recorded and stored in a digital format.

\section{Analysis \& Results}

The collected data was analyzed using a thematic analysis procedure. In this popular and flexible method to analyze interview data, the researcher constructs central themes and subthemes and then applies this framework to the data. The themes are related to the research question and the researcher invents them after thematic coding of the interview notes. After the themes and subthemes are determined they are used to categorize all the data. This is done in a spreadsheet where the themes are columns and the snippets of interview notes are placed under each column [25].

Five main themes arose from the interviews, namely 1) Reading data from the platform, 2) Writing data to the platform, 3) Partnership benefits, 4) Size and reach of the platform, 5) Collaboration with healthcare industry. Each of the five themes consisted of sub-themes. The themes and their subthemes are described in the following. Table 1 summarizes the themes and sub-themes and presents descriptive statistics about their occurrences in the interviews [8].

The first main theme was related to leveraging the pool of data generated by the connected of applications and devices in the ecosystem. Key benefits of reading data from the platform included 1) obtain a richer set data on the user, 2) Simplify user experience and, 3) Reduce development work and costs. All of the interviewees felt that obtaining a diverse set of data on the user and gaining access to a pool of health and fitness data could be used to improve their company's products.

User experience (UX) was emphasized by companies using a platform. The main value was seen in replacing manual data input with automatic data access from the platform. By eliminating a need to type in basic information, the use of the product was made more effortless. Also improving the product's UX by designing it to fit the native experience of the platform was mentioned. In the past, connections with other applications and devices required separate integration and required considerable engineering work. There were few platform services for easy integrations, but the studied digital health platforms had the advantage of integrated data storage for all user data in one place. This was seen as an opportunity to reduce development work and costs. 
Table 1. Themes and subthemes of the interviews $(\mathrm{N}=7)$.

\begin{tabular}{|c|c|c|c|c|c|c|c|}
\hline Theme & Sub-theme & $\begin{array}{l}\text { No of } \\
\text { companies who } \\
\text { mentioned this } \\
\text { theme }\end{array}$ & $\begin{array}{l}\text { No of } \\
\text { companies } \\
\text { already using } \\
\text { the platforms } \\
\text { who mentioned } \\
\text { this theme }\end{array}$ & $\begin{array}{l}\text { No of } \\
\text { companies who } \\
\text { are not using the } \\
\text { platforms and } \\
\text { mentioned this } \\
\text { theme }\end{array}$ & $\begin{array}{c}\text { No of } \\
\text { companies who } \\
\text { mentioned this } \\
\text { theme in the } \\
\text { context of Apple } \\
\text { Healthkit }\end{array}$ & $\begin{array}{l}\text { No of } \\
\text { companies who } \\
\text { mentioned this } \\
\text { theme in the } \\
\text { context of } \\
\text { Google Fit }\end{array}$ & $\begin{array}{c}\text { No of } \\
\text { companies who } \\
\text { mentioned this } \\
\text { theme in the } \\
\text { context of } \\
\text { domestic } \\
\text { platform }\end{array}$ \\
\hline \multirow{3}{*}{$\begin{array}{l}\text { 1) Reading data } \\
\text { from the platform }\end{array}$} & $\begin{array}{l}\text { Access to richer } \\
\text { set of information } \\
\text { on the users }\end{array}$ & $7 / 7$ & $3 / 3$ & $4 / 4$ & $7 / 7$ & $3 / 7$ & $1 / 7$ \\
\hline & $\begin{array}{l}\text { Simplify user } \\
\text { experience }\end{array}$ & $2 / 7$ & $2 / 3$ & 0 & $2 / 7$ & 0 & 0 \\
\hline & $\begin{array}{c}\text { Reduce } \\
\text { development work } \\
\text { and cost }\end{array}$ & $3 / 7$ & $1 / 3$ & $2 / 4$ & $3 / 7$ & $1 / 7$ & $1 / 7$ \\
\hline \multirow{2}{*}{$\begin{array}{l}\text { 2) Writing data to } \\
\text { the platform }\end{array}$} & $\begin{array}{l}\text { Give users power } \\
\text { to use data and } \\
\text { share their data }\end{array}$ & $4 / 7$ & $3 / 3$ & $1 / 4$ & $4 / 7$ & $3 / 7$ & $2 / 7$ \\
\hline & $\begin{array}{c}\text { Give b2b access to } \\
\text { data over the } \\
\text { platform }\end{array}$ & $1 / 7$ & $1 / 3$ & 0 & 0 & 0 & $1 / 7$ \\
\hline \multirow{2}{*}{$\begin{array}{l}\text { 3) Partnership } \\
\text { benefits }\end{array}$} & $\begin{array}{c}\text { Capture marketing } \\
\text { value }\end{array}$ & $4 / 7$ & $2 / 3$ & $2 / 4$ & $4 / 7$ & $2 / 7$ & $0 / 7$ \\
\hline & $\begin{array}{c}\text { Form synergist } \\
\text { relationships }\end{array}$ & $3 / 7$ & $2 / 3$ & $1 / 4$ & $3 / 7$ & $2 / 7$ & $1 / 7$ \\
\hline $\begin{array}{l}\text { 4) Size and reach } \\
\text { of the platform }\end{array}$ & $\begin{array}{l}\text { Reach to and } \\
\text { affect as many } \\
\text { customers as } \\
\text { possible }\end{array}$ & $7 / 7$ & $3 / 3$ & $4 / 4$ & $7 / 7$ & $5 / 7$ & 0 \\
\hline \multirow{3}{*}{$\begin{array}{l}\text { 5) Collaboration } \\
\text { with healthcare } \\
\text { industry }\end{array}$} & $\begin{array}{l}\text { Pilot a product in } \\
\text { familiar } \\
\text { environment }\end{array}$ & $1 / 7$ & $1 / 3$ & 0 & 0 & 0 & $1 / 7$ \\
\hline & $\begin{array}{l}\text { Use data for } \\
\text { diagnosis and } \\
\text { treatment }\end{array}$ & $2 / 7$ & $2 / 3$ & 0 & $2 / 7$ & 0 & $1 / 7$ \\
\hline & $\begin{array}{c}\text { Become pioneer in } \\
\text { predictive } \\
\text { healthcare }\end{array}$ & $4 / 7$ & $3 / 3$ & $1 / 4$ & $3 / 7$ & 0 & $2 / 7$ \\
\hline
\end{tabular}

The second main theme, writing data to the platform included subthemes about giving users the power to use and share their own data, and making it possible to give B2B customers access to data over the platform. This would allow complementors to the platform to share data between each other directly, if permitted by the end user. Companies that already used platforms saw writing code for the platform as more beneficial. This was also linked to the partnership benefits subtheme.

One key digital health platform benefit is the data to the user whenever new data is entered. The users then use the data as they wish and share it with other applications. One company mentioned an idea of how privacy conscious consumers may start favoring applications that enable them to control their own data over the platforms. 
The third main theme was partnership benefits. In some cases, complementor strategies were related to wider synergistic reasons such as capturing marketing value or seeking to form in-depth relationships with global platform owners. Benefits were expected from new connections or getting feedback and developing products together with the platform owner. These were especially important for companies that already complemented platforms. They pointed out noticeable benefits in terms of sales and download after platform integration. Key sub-themes related to partnership benefits included: 1) Capture marketing value and 2) Forming synergistic relationships.

The fourth main theme was size and reach of the platform. All of the interviewed companies planned to expand into international markets. Because of this, the domestic platform was not considered as a very attractive option. However, a domestic platform was mentioned as a vehicle to pilot and test new products in a small, easily approachable market. Key points in this category included: 1) Reaching and affecting as many customers as possible. 2) Piloting a product in a familiar and accessible environment. One of the main perceived benefits of a global platform was the potential to reach and affect large international user base.

Collaboration with the healthcare industry was identified as the fifth main theme. All of the interviewed companies did business in self-monitoring, lifestyle or preventive healthcare sectors, and not in clinical patient care. Possibly for this, collaboration with the healthcare industry was considered interesting but difficult, and it was not a primary reason for starting to use a platform. Merely, the companies already using a platform considered it as a long-term opportunity.

Key issues mentioned regarding collaboration with the healthcare industry were: 1) Produce data to be used as part of diagnosis and treatment, and 2) Be a pioneer in predictive healthcare. The domestic platform included data about health records such as doctor reports, descriptions and lab tests. In addition to storing self-reported fitness data, the domestic platform was already used by healthcare providers, which provided additional opportunities.

\section{Findings and Synthesis: Service Platform Complementor Strategies}

Table 2 gathers the themes and subthemes arising from the data in conjunction to the effectual reasoning principles [7] that are 1) Exploiting and leveraging environmental contingencies, 2) Emphasizing strategic alliances and pre-commitments, 3) Controlling the unpredictable future, and 4) Affordable loss. When elaborating the themes in the light of the effectual reasoning principle many starting points for complementor strategy can be summarized.

Three of the four effectuation principles can be straightforwardly connected to the themes and subthemes drawn from the interviews. The affordable loss principle, is not intuitively very dominant, but can be thought of as highly important when a new product or service is being tested in an environment that is 
Table 2. Complementor strategies constructed from the interviews and effectual reasoning principles by Sarasvathy (2001).

\begin{tabular}{|c|c|c|}
\hline Effectual reasoning principle & Themes from the data & Complementor strategies \\
\hline $\begin{array}{l}\text { Exploiting and leveraging environ- } \\
\text { mental contingencies }\end{array}$ & $\begin{array}{l}\text { Partnership Benefits } \\
\text { Size and Reach of the platforms } \\
\text { Reading Data }\end{array}$ & $\begin{array}{l}\text { - Establish relationships with other actors in the market } \\
\text { - Getting help in marketing and creating new } \\
\text { opportunities of reaching more customers } \\
\text { - Using a platform as a source of unexpected data }\end{array}$ \\
\hline $\begin{array}{l}\text { Emphasizing strategic alliances and } \\
\text { pre-commitments }\end{array}$ & Collaboration with healthcare industry & $\begin{array}{l}\text { Opportunity to self-select appropriate pilot users and } \\
\text { partners } \\
\text { - Forming alliances to shaping user experience, improve } \\
\text { storage of data, invest in marketing and scale business } \\
\text { - Possibility of engaging other complementors in } \\
\text { investing in joint ventures }\end{array}$ \\
\hline Controlling the unpredictable future & $\begin{array}{l}\text { Partnership Benefits } \\
\text { Size and Reach of the platforms } \\
\text { Writing data } \\
\text { Data }\end{array}$ & $\begin{array}{l}\text { Possibility of co-creating value with existing platform } \\
\text { participants } \\
\text { - } \text { Grow with the platform } \\
\text { - Staying ahead of the competitors by creating future } \\
\text { user experience from the data in the platform } \\
\text { - Leverage in marketing efforts } \\
\text { - Possibilities of introducing offerings to market }\end{array}$ \\
\hline Affordable loss & Collaboration with healthcare industry & $\begin{array}{l}\text { Possibility of testing new product or service in an } \\
\text { environment familiar to end users }\end{array}$ \\
\hline
\end{tabular}

familiar for end users and when end users are allowed access to data without knowing exactly how it will benefit other users.

From the exploiting contingencies principle point of view, strategies are related to opening new relationships to other actors in the market, helping in marketing and creating new opportunities of reaching more customers as the platform emerges and creates its markets. Platforms were also considered as source of unexpected data that can be used to create competitive edge.

Strategic alliances point of view of effectuation was more multi-faceted compared to exploiting a contingency principle. There, the opportunity to self-select appropriate pilot users and partners can be thought of as a priority for an application developer. Alliances can then be used to improve user experience, improve storage of data, invest in marketing and to scale business. The possibility of engaging other complementors to invest and co-create a venture together also emerged from the analysis as a motive.

Controlling the unpredictable future this perspective shows in the application of the developer's strategies as a possibility of co-creating value with existing platform participants and growing with the platform. Also staying ahead of the competitors by creating future user experiences from the data in the platform, leverage in marketing efforts and possibilities of introducing offerings to the market was notable in the interviews.

\section{Discussion}

This paper presented an entrepreneurial logic approach to complementors' strategies in service platforms. There are very few prior studies on effectual reasoning in complementors' strategy selection, which motivated our study. An ef- 
fectual reasoning lens provided insight into elaborating the complementor's strategies in the context of emerging digital health platforms. The results imply that effectual reasoning gives framework for strategic planning, which allows suggesting that innovation activities in emerging service platforms are by nature effectual, not causal. Emerging digital service platforms offer context to study next-generation way of organizing for innovation, and support novel ways to think about entrepreneurship. Empirical data implied increased role of non-technical core elements and the role of other complementors in ad hoc collaboration and extended market reach. Effectual reasoning principles can be used as the parameters for exploring complementors' strategies. Increased uncertainty may be negative when approached from a causal reasoning point of view, but for those companies with an effectual reasoning orientation, uncertainty poses great opportunities for success as the selected strategy is merely a starting point in the relation with the platform.

The theoretical contributions of this paper are twofold. Firstly, this paper extends the construct of value co-creation [26] [27] [28] [29], to cover complementors' innovation activities in digital service platforms. Secondly, this paper extends the construct of platform core to cover non-technological modules to better understand the dynamics of service platforms' emerge and grow. The entrepreneurial logic extension to platforms allows the treatment of platforms as evolutionary and dynamic environments, instead of stable, fixed structural arrangements as conceptualized from an engineering point of view. Effectual reasoning is proposed as an approach to complementors' strategic planning in these dynamic ecosystems.

Despite of the contributions, this paper has limitations that provide motivation for further research. Small sample size and convenience sampling render this study as not fully representative. During the time of the study, technology firms complementing digital health platforms and available for an interview were limited. Small sample size is counterbalanced with the strong expertise of the interviewees and detailed data analysis. The same issues were repeated as the interviews progressed suggesting saturation in themes and subthemes. Another limitation relates to the research design of the study. Since the entrepreurial orientation of firms is challenging to measure, and is under debate e.g. [30], the identified themes and subthemes were categorized according to effectual reasoning principles, resulting in overall understanding that the strategies reflect effectuation logic.

The combination of digital platforms and entrepreneurial logic is a fruitful arena for further research. Service platforms are a fairly new phenomenon, and lack data, theories and concepts to understand their dynamics. It is evident that service platforms involve socio-economical network relationships beyond anonymous market transactions that cannot be fully explained with earlier engineering or economics perspectives. The notion of value co-creation and effectual reasoning may add to our understanding of the competitive dynamics of platform economy. 


\section{Managerial Implications}

The managerial implication of this paper is that complementors can develop its' complement not only based on the platform owner's technology, but also based on non-technological elements, which broadens their strategic options and positioning in the platform ecosystem. An emerging platform makes inside-out, and outside-in type of knowledge transfer possible c.f. [31], and enables co-creation of new knowledge with complementary partners c.f. [32] creating opportunities for new types of complementors and niche providers.

\section{Conflicts of Interest}

The authors declare no conflicts of interest regarding the publication of this paper.

\section{References}

[1] Jansen, S. and Cusumano, M.A. (2013) Defining Software Ecosystems: A Survey of Software Platforms and Business Network Governance. In: Jansen, S., Brinkkemper, S. and Cusumano, M.A., Eds., Software Ecosystems, Edward Elgar Publishing, Cheltenham, U.K. and Northampton, Mass, 13-28. https://doi.org/10.4337/9781781955635.00008

[2] Choi, J.P. (2010) Tying in Two-Sided Markets with Multi-Homing. The Journal of Industrial Economics, 58, 607-627. https://doi.org/10.1111/j.1467-6451.2010.00426.x

[3] Tiwana, A. (2014) Platform Ecosystems: Aligning Architecture, Governance, and Strategy. Morgan Kaufmann, Waltham, MA.

[4] Breidbach, C.F., Brodie, R., Hollebeek, L. and Breidbach, C.F. (2014) Beyond Virtuality: From Engagement Platforms to Engagement Ecosystems. Managing Service Quality, 24, 592-611. https://doi.org/10.1108/MSQ-08-2013-0158

[5] Gawer, A. (2014) Bridging Differing Perspectives on Technological Platforms: Toward an Integrative Framework. Research Policy, 43, 1239-1249. https://doi.org/10.1016/j.respol.2014.03.006

[6] Baldwin, C.Y. and Woodard, J.C. (2009) The Architecture of Platforms: A Unified View. In: Gawer, A., Ed., Platforms, Markets and Innovation, Edward Elgar Publishing, Cheltenham, U.K. and Northampton, Mass, 19-44. https://doi.org/10.4337/9781849803311.00008

[7] Sarasvathy, S. (2001) Toward Causation and Effectuation: A Theoritical Shift from Inevitability to Economic Entrepreneurial Contingency. The Academy of Management Review, 26, 243-263. https://doi.org/10.5465/amr.2001.4378020

[8] Rautsi, E. (2014) Co-Creating Value: Digital Health and Fitness Platforms. Master's thesis, Aalto University, Aalto.

[9] Gawer, A. and Cusumano, M.A. (2002) Platform Leadership: How Intel, Microsoft, and Cisco Drive Industry Innovation. Harvard Business School Press, Boston.

[10] Tiwana, A., Konsynski, B. and Bush, A.A. (2010) Platform Evolution: Coevolution of Platform Architecture, Governance, and Environmental Dynamics. Information Systems Research, 21, 675-687. https://doi.org/10.1287/isre.1100.0323

[11] Chesbrough, H. (2011) Open Services Innovation. Jossey-Brass, San Francisco.

[12] Paul, S. (2015) Platform Scale (Forthcoming). Publishizer. 
[13] Maglio, P.P. and Spohrer, J. (2008) Fundamentals of Service Science. Journal of the Academy of Marketing Science, 36, 18-20. https://doi.org/10.1007/s11747-007-0058-9

[14] Powell, W.W. (1990) Neither Market Nor Hierarchy: Network Forms of Organization. Research in Organizational Behavior, 12, 295-336.

[15] Gawer, A. and Cusumano, M.A. (2008) How Companies Become Platform Leaders. MIT Sloan Management Review, 49, 28-35.

[16] Dew, N., Read, S., Sarasvathy, S.D. and Wiltbank, R. (2008) Outlines of a Behavioral Theory of the Entrepreneurial Firm. Journal of Economic Behavior and Organization, 66, 37-59. https://doi.org/10.1016/j.jebo.2006.10.008

[17] Wiltbank, R., Dew, N., Read, S. and Sarasvathy, S.D. (2006) What to Do Next? The Case for Non-Predictive Strategy. Strategic Management Journal, 27, 981-998. https://doi.org/10.1002/smj.555

[18] Perry, J.T., Chandler, G.N. and Markova, G. (2012) Entrepreneurial Effectuation: A Review and Suggestions for Future Research. Entrepreneurship: Theory and Practice, 36, 837-861. https://doi.org/10.1111/j.1540-6520.2010.00435.x

[19] Dew, N. and Sarasvathy, S.D. (2007) Innovations, Stakeholders \& Entrepreneurship. Journal of Business Ethics, 74, 267-283. https://doi.org/10.1007/s10551-006-9234-y

[20] Read, S., Dew, N., Sarasvathy, S.D., Song, M. and Wiltbank, R. (2009) Marketing under Uncertainty: The Logic of an Effectual Approach. Journal of Marketing, 73, 1-18. https://doi.org/10.1509/jmkg.73.3.1

[21] Read, S. and Sarasvathy, S.D. (2005) Knowing What to Do and Doing What You Know. The Journal of Private Equity, 9, 45-62. https://doi.org/10.3905/jpe.2005.605370

[22] Ramaswamy, V. and Gouillart, F. (2010) Building the Co-Creative Enterprise. Harvard Business Review, 88, 100-109.

[23] Wiltbank, R., Read, S., Dew, N. and Sarasvathy, S.D. (2009) Prediction and Control under Uncertainty: Outcomes in Angel Investing. Journal of Business Venturing, 24, 116-133. https://doi.org/10.1016/j.jbusvent.2007.11.004

[24] Maine, E., Soh, P.H. and Dos Santos, N. (2015) The Role of Entrepreneurial Decision-Making in Opportunity Creation and Recognition. Technovation, 39-40, 53-72.

[25] Bryman, A. (2012) Social Research Methods.

[26] Vargo, S.L. and Lusch, F.R. (2004) Evolving to a New Dominant Logic for Marketing. Journal of Marketing, 68, 1-17.

[27] Vargo, S.L. and Lusch, F.R. (2008) From Goods to Service(s): Divergences and Convergences of Logics. Industrial Marketing Management, 37, 254-259. https://doi.org/10.1016/j.indmarman.2007.07.004

[28] Ramirez, R. (1999) Value Co-Production: Intellectual Origins and Implications for Practice and Research. Strategic Management Journal, 20, 49-65. https://doi.org/10.1002/(SICI)1097-0266(199901)20:1<49::AID-SMJ20>3.0.CO;2-2

[29] Grönroos, C. (2008) Service Logic Revisited: Who Creates Value? And Who Co-Creates? European Business Review, 20, 298-314. https://doi.org/10.1108/09555340810886585

[30] Anderson, B.S., Kreiser, P.M., Kuratko, D.F., Hornsby, J.S. and Eshima, Y. (2015) Reconceptualizing Entrepreneurial Orientation. Strategic Management Journal, 36, 1579-1596. https://doi.org/10.1002/smj.2298 
[31] Chesbrough, H. (2003) Open Innovation: The New Imperative for Creating and Profiting from Technology. Harvard Business School Press, Boston.

[32] Enkel, E., Gassmann, O. and Chesbrough, H. (2009) Open R \& D and Open Innovation: Exploring the Phenomenon. $R$ and $D$ Management, 39, 311-316. https://doi.org/10.1111/j.1467-9310.2009.00570.x 